\title{
Water quality of the surfaces waters of the swimming pools port in Swinoujscie
}

\section{Ocena jakości wód powierzchniowych w basenach portowych w Świnoujściu}

\author{
Piotr Daniszewski ${ }^{1}$, Beata Draszawka - Bołzan ${ }^{2}$ \\ ${ }^{1}$ Katedra Zoologii Bezkręgowców i Limnologii, Uniwersytet Szczeciński \\ ul. Wąska 13, 71-415 Szczecin, Poland, \\ ${ }^{2}$ Katedra Chemii i Ochrony Środowiska Wodnego, Wydział Biologii, Uniwersytet Szczeciński, \\ ul. Felczaka 3C, 71-412 Szczecin, Poland \\ E-mail address: daniszewski@univ.szczecin.pl
}

\begin{abstract}
To estimate differentiation of water chemistry in reservoirs of swimming pools port in Swinoujscie, in time of 2004 - 2008. In arbitrary appointed times 5 physical and chemical indicators of water quality were determined to evaluate general status and water condition - temperature, $\mathrm{pH}, \mathrm{COD}-$ $\mathrm{Cr}, \mathrm{BOD}_{5}, \mathrm{Cl}^{-}$.
\end{abstract}

\section{Keywords:}

swimming pools port; natural water quality; temperature; $\mathrm{pH}, \mathrm{COD}-\mathrm{Cr} ; \mathrm{BOD}_{5} ; \mathrm{Cl}^{-}$

\section{STRESZCZENIE}

Celem niniejszej pracy było prześledzenie w okresie od 2004 do 2008 roku poziomu oraz dynamiki zmian w wodach basenów portowych Portu Świnoujście parametrów ogólnych jakości wód. W pracy oznaczano wskaźniki ogólne wody: temperaturę, $\mathrm{pH}$, ChZT-Cr, $\mathrm{BZT}_{5}, \mathrm{Cl}^{-}$. Wszystkie oznaczenia i obliczenia wykonywano według metod zalecanych przez Polskie Normy, stosując procedury analityczne opisane m.in. przez Dojlido, Elbanowska, Hermanowicza.

\section{Stowa kluczowe:}

baseny portowe, jakość wód, temperatura, $\mathrm{pH}, \mathrm{ChZT}-\mathrm{Cr}, \mathrm{BZT}_{5}, \mathrm{Cl}^{-}$

\section{WPROWADZENIE}

Zbiorniki wodne należą do cennych elementów środowiska przyrodniczego w związku z czym powinny być objęte właściwą ochroną [1,3,5-9]. Akweny wodne pełnią wiele ról w środowisku naturalnym $[1,2,7-10,12]$. Do najważniejszych należy zaliczyć następujące role: hydrologiczną, mikroklimatyczną, hydrosanitarną, przemysłową [12,14,16,18,19]. Mając na uwadze Ramową Dyrektywą Wodną, która nakłada na Polskę obowiązek, aby do 2015 r. wszystkie wody, w tym również wody w akwenach portowych, posiadały dobry stan ekologiczny $[1,3,4,6-9,12,15,16,19]$. Baseny portowe należą do akwenów, których wody są 
szczególnie narażone na zanieczyszczenia w związku z przeładunkami jakie maja miejsce na ich terenie [11,13,20,21-26]. Podstawową funkcją Portu w Świnoujściu jest przeładunek zboża, rud, olejów, papieru, celulozy, drobnicy, węgla, żelaza [20,21,24-28].

\section{CZECŚĆ DOŚWIADCZALNA}

Badania zostały przeprowadzone na terenie 3 basenów portowych Portu Świnoujście (Baseny: Bałtycki, Atlantycki, i Zachodni) w miesiącach czerwiec - wrzesień 2004 - 2008.

Port Świnoujście jest to port morski położony nad Zatoką Pomorską, na południowym wybrzeżu Morza Bałtyckiego, na wyspach Uznam i Wolin [25-28]. Port usytuowany w cieśninie Świny, w Świnoujściu, w województwie zachodniopomorskim [2528]. Do portu mogą być wprowadzane statki o maksymalnej długości $260,0 \mathrm{~m}$, szerokości 42,0 $\mathrm{m}$ i zanurzeniu 12,8 m [25-28]. Pływy w porcie nie występują, ale możliwe są wahania poziomu wody z nagłymi prądami wchodzącymi oraz wychodzących, które w zależności od kierunku wiatrów i osiągać prędkość do 1,5 węzła [25-28]. Przy wejściu do portu przy zachodnim falochronie, znajduje się Mielizna Zachodnia [25-28]. Podczas zimy, port jest zazwyczaj wolny od lodu. Zalodzenie basenów portowych i redy występuje dopiero po okresach długotrwałych mrozów [25-28]. Na mapie nr 1 przedstawiono usytuowanie Portu w Świnoujściu.

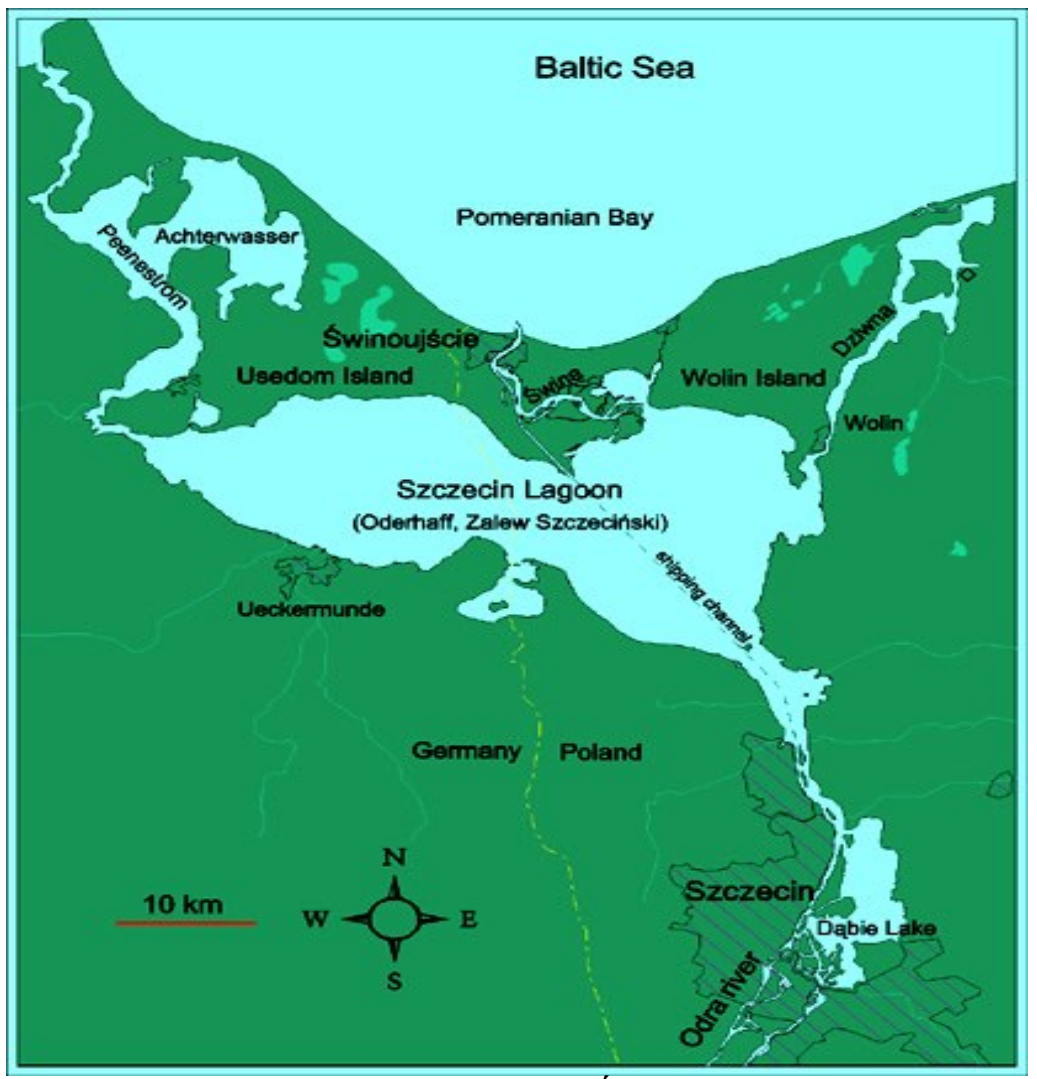

Mapa 1. Usytuowanie Portu w Świnoujściu [27, 28]. 
Na mapie nr 2 przedstawiono rozmieszczenie kanałów i nabrzeży Portu w Świnoujściu.

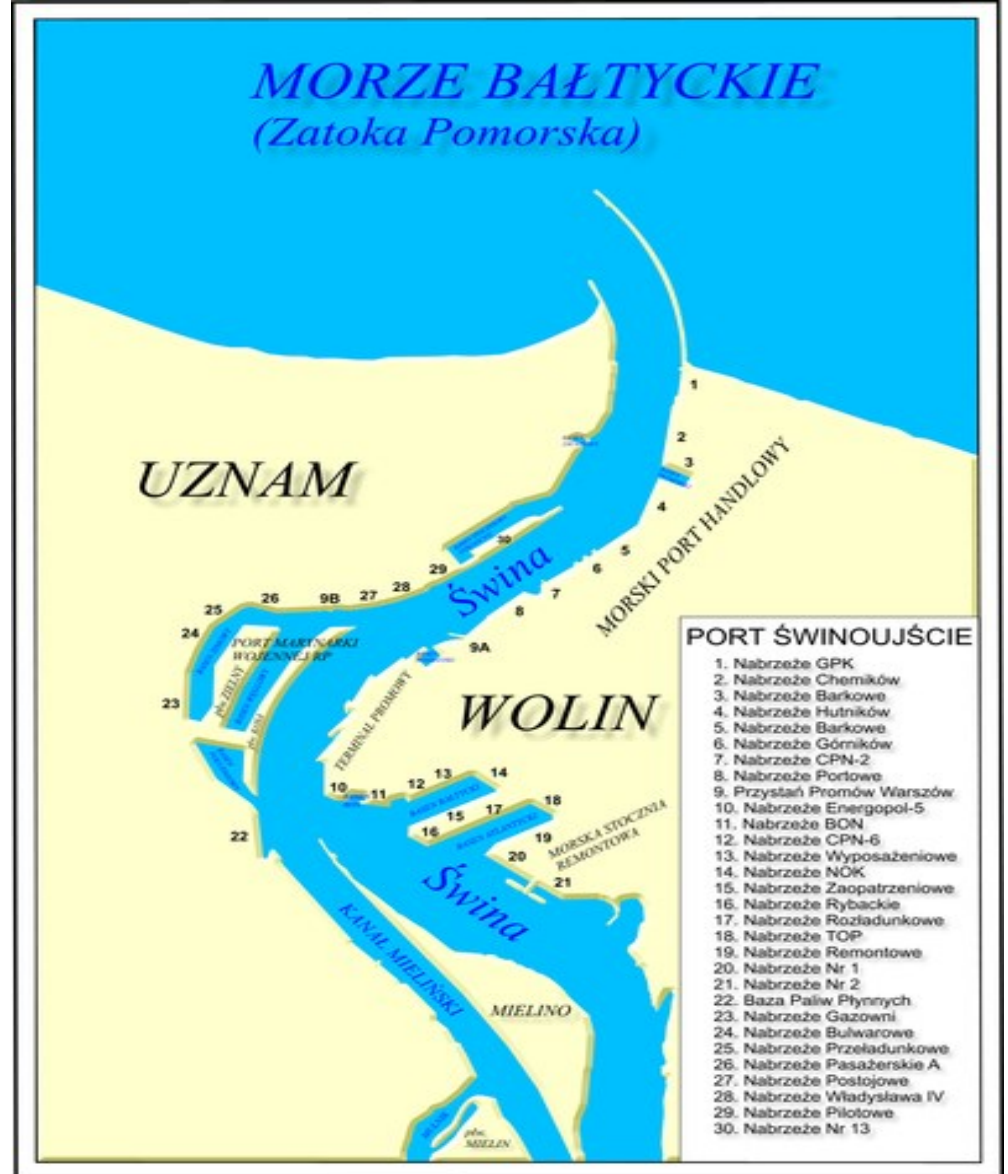

Mapa 2. Rozmieszczenie kanałów i nabrzeży Portu w Świnoujściu [27-28].

Próby wody do badań pobierano według PN/C-04632.03 z głębokości ok. 0,5 m poniżej lustra wody. W miejscu poboru prób oznaczano temperaturę, $\mathrm{pH}$. Pobrane próbki wody zostały utrwalane zgodnie z zaleceniami zawartymi w Polskiej Normie - PN/C04632.04. Pozostałe wskaźniki określające jakość wód zostały oznaczone w przeciągu 24 godzin od momentu pobrania prób. Oznaczenie ilości rozpuszczonej materii organicznej podatnej na utlenienie określano jako ChZT zgodnie z PN/C-04578.02, stężenie chlorków oznaczano zgodnie z PN/C-04617.02.

Poszczególne wskaźników jakości wód oceniano według kryteriów zalecanych do oceniania śródlądowych wód powierzchniowych określonych w Rozporządzeniu Ministra Środowiska z dnia 11 lutego 2004 r. w sprawie klasyfikacji dla prezentowania stanu wód powierzchniowych i podziemnych, sposobu prowadzenia monitoringu oraz sposobu interpretacji wyników i prezentacji stanu tych wód.

\section{DYSKUSJA WYNIKÓW I WNIOSKI}

Wyniki badań wskaźników jakości wód powierzchniowych basenów portowych Portu Świnoujście za okres 2004 - 2008 wraz z klasyfikacją wartości badanych wskaźników wg kryteriów Rozporządzenia Ministra Środowiska z dnia 11 lutego 2004 r. przedstawiono w tabelach od 1 do 5. 
Tabela 1. Wyniki badań wskaźników jakości wód powierzchniowych basenów portowych Portu Świnoujście w 2004 roku wraz z klasyfikacją wartości badanych wskaźników wg kryteriów Rozporządzenia Ministra Środowiska z dnia 11 lutego 2004 r.

\begin{tabular}{|l|c|c|c|c|c|}
\hline \multirow{3}{*}{ Badany basen } & \multicolumn{5}{|c|}{ Wskaźnik jakości wód (jednostki) } \\
\cline { 2 - 6 } & $\begin{array}{c}\mathrm{pH} \\
(\mathrm{jedn} . \mathrm{pH})\end{array}$ & $\begin{array}{c}\text { Temperatura } \\
\text { wody }\left({ }^{\circ} \mathrm{C}\right)\end{array}$ & $\begin{array}{c}\mathrm{ChZT}^{-C r} \\
\left(\mathrm{mg} \mathrm{O}_{2} \cdot \mathrm{dm}^{-3}\right)\end{array}$ & $\begin{array}{c}\mathrm{BZT}_{5} \\
\left(\mathrm{mg} \mathrm{O}_{2} \cdot \mathrm{dm}^{-3}\right)\end{array}$ & $\begin{array}{c}\mathrm{Cl}^{-} \\
\left(\mathrm{mg} \mathrm{Cl}^{-} \mathrm{dm}^{-3}\right)\end{array}$ \\
\hline Atlantycki & $7,82(\mathrm{I})$ & $13,6(\mathrm{I})$ & $26(\mathrm{III})$ & $3,78(\mathrm{III})$ & $985(\mathrm{~V})$ \\
\hline Baltycki & $7,88(\mathrm{I})$ & $15,2(\mathrm{I})$ & $22(\mathrm{III})$ & $3,48(\mathrm{III})$ & $1274(\mathrm{~V})$ \\
\hline Trymerski & $7,94(\mathrm{I})$ & $15,0(\mathrm{I})$ & $27(\mathrm{III})$ & $4,15(\mathrm{III})$ & $1096(\mathrm{~V})$ \\
\hline
\end{tabular}

Objaśnienia: I, III, V - klasyfikacja wartości badanego wskaźnika wg kryteriów Rozporządzenia Ministra Środowiska z dnia 11 lutego 2004 r.

Tabela 2. Wyniki badań wskaźników jakości wód powierzchniowych basenów portowych Portu Świnoujście w 2005 roku wraz z klasyfikacją wartości badanych wskaźników wg kryteriów Rozporządzenia Ministra Środowiska z dnia 11 lutego 2004 r.

\begin{tabular}{|l|c|c|c|c|c|}
\hline \multirow{2}{*}{ Badany basen } & \multicolumn{5}{|c|}{ Wskaźnik jakości wód (jednostki) } \\
\cline { 2 - 6 } & $\begin{array}{c}\mathrm{pH} \\
(\text { jedn. } \mathrm{pH})\end{array}$ & $\begin{array}{c}\text { Temperatura } \\
\text { wody }\left({ }^{\circ} \mathrm{C}\right)\end{array}$ & $\begin{array}{c}\mathrm{ChZT}^{-C r} \\
\left(\mathrm{mg} \mathrm{O}_{2} \cdot \mathrm{dm}^{-3}\right)\end{array}$ & $\begin{array}{c}\mathrm{BZT}_{5} \\
\left(\mathrm{mg} \mathrm{O}_{2} \cdot \mathrm{dm}^{-3}\right)\end{array}$ & $\begin{array}{c}\mathrm{Cl}^{-} \\
\left(\mathrm{mg} \mathrm{Cl}^{-} \mathrm{dm}^{-3}\right)\end{array}$ \\
\hline Atlantycki & $7,97(\mathrm{I})$ & $15,1(\mathrm{I})$ & $34(\mathrm{IV})$ & $3,85(\mathrm{III})$ & $1087(\mathrm{~V})$ \\
\hline Baltycki & $7,78(\mathrm{I})$ & $15,0(\mathrm{I})$ & $32(\mathrm{IV})$ & $2,97(\mathrm{II})$ & $1251(\mathrm{~V})$ \\
\hline Trymerski & $7,96(\mathrm{I})$ & $14,7(\mathrm{I})$ & $35(\mathrm{IV})$ & $3,80(\mathrm{III})$ & $1130(\mathrm{~V})$ \\
\hline
\end{tabular}

Objaśnienia: I, II, III, IV, V - klasyfikacja wartości badanego wskaźnika wg kryteriów Rozporządzenia Ministra Środowiska z dnia 11 lutego 2004 r.

Tabela 3. Wyniki badań wskaźników jakości wód powierzchniowych basenów portowych Portu Świnoujście w 2006 roku wraz z klasyfikacją wartości badanych wskaźników wg kryteriów Rozporządzenia Ministra Środowiska z dnia 11 lutego 2004 r.

\begin{tabular}{|l|c|c|c|c|c|}
\hline \multirow{2}{*}{ Badany basen } & \multicolumn{5}{|c|}{ Wskaźnik jakości wód (jednostki) } \\
\cline { 2 - 6 } & $\begin{array}{c}\mathrm{pH} \\
(\mathrm{jedn} . \mathrm{pH})\end{array}$ & $\begin{array}{c}\text { Temperatura } \\
\text { wody }\left({ }^{\circ} \mathrm{C}\right)\end{array}$ & $\begin{array}{c}\mathrm{ChZT}^{-C r} \\
\left(\mathrm{mg} \mathrm{O}_{2} \cdot \mathrm{dm}^{-3}\right)\end{array}$ & $\begin{array}{c}\mathrm{BZT}_{5} \\
\left(\mathrm{mg} \mathrm{O}_{2} \cdot \mathrm{dm}^{-3}\right)\end{array}$ & $\begin{array}{c}\mathrm{Cl}^{-} \\
\left(\mathrm{mg} \mathrm{Cl}^{-} \mathrm{dm}^{-3}\right)\end{array}$ \\
\hline Atlantycki & $7,94(\mathrm{I})$ & $15,0(\mathrm{I})$ & $34(\mathrm{IV})$ & $3,77(\mathrm{III})$ & $1104(\mathrm{~V})$ \\
\hline Baltycki & $7,91(\mathrm{I})$ & $15,3(\mathrm{I})$ & $32(\mathrm{IV})$ & $3,92(\mathrm{III})$ & $1240(\mathrm{~V})$ \\
\hline Trymerski & $7,86(\mathrm{I})$ & $14,5(\mathrm{I})$ & $35(\mathrm{IV})$ & $3,16(\mathrm{III})$ & $1096(\mathrm{~V})$ \\
\hline
\end{tabular}

Objaśnienia: I, II, IV, V - klasyfikacja wartości badanego wskaźnika wg kryteriów Rozporządzenia Ministra Środowiska z dnia 11 lutego 2004 r. 
Tabela 4. Wyniki badań wskaźników jakości wód powierzchniowych basenów portowych Portu Świnoujście w 2007 roku wraz z klasyfikacją wartości badanych wskaźników wg kryteriów Rozporządzenia Ministra Środowiska z dnia 11 lutego 2004 r.

\begin{tabular}{|l|c|c|c|c|c|}
\hline \multirow{3}{*}{ Badany basen } & \multicolumn{5}{|c|}{ Wskaźnik jakości wód (jednostki) } \\
\cline { 2 - 6 } & $\begin{array}{c}\mathrm{pH} \\
(\mathrm{jedn} . \mathrm{pH})\end{array}$ & $\begin{array}{c}\text { Temperatura } \\
\text { wody }\left({ }^{\circ} \mathrm{C}\right)\end{array}$ & $\begin{array}{c}\mathrm{ChZT}^{-C r} \\
\left(\mathrm{mg} \mathrm{O}_{2} \cdot \mathrm{dm}^{-3}\right)\end{array}$ & $\begin{array}{c}\mathrm{BZT}_{5} \\
\left(\mathrm{mg} \mathrm{O}_{2} \cdot \mathrm{dm}^{-3}\right)\end{array}$ & $\begin{array}{c}\mathrm{Cl}^{-} \\
\left(\mathrm{mg} \mathrm{Cl}^{-} \mathrm{dm}^{-3}\right)\end{array}$ \\
\hline Atlantycki & $7,85(\mathrm{I})$ & $15,0(\mathrm{I})$ & $34(\mathrm{IV})$ & $3,62(\mathrm{III})$ & $984(\mathrm{~V})$ \\
\hline Baltycki & $7,94(\mathrm{I})$ & $14,5(\mathrm{I})$ & $38(\mathrm{IV})$ & $3,45(\mathrm{III})$ & $1307(\mathrm{~V})$ \\
\hline Trymerski & $7,93(\mathrm{I})$ & $14,7(\mathrm{I})$ & $32(\mathrm{IV})$ & $3,81(\mathrm{III})$ & $1293(\mathrm{~V})$ \\
\hline
\end{tabular}

Objaśnienia: I, III, IV, V - klasyfikacja wartości badanego wskaźnika wg kryteriów Rozporządzenia Ministra Środowiska z dnia 11 lutego 2004 r.

Tabela 5. Wyniki badań wskaźników jakości wód powierzchniowych basenów portowych Portu Świnoujście w 2008 roku wraz z klasyfikacją wartości badanych wskaźników wg kryteriów Rozporządzenia Ministra Środowiska z dnia 11 lutego 2004 r.

\begin{tabular}{|c|c|c|c|c|c|}
\hline \multirow[t]{2}{*}{ Badany basen } & \multicolumn{5}{|c|}{ Wskaźnik jakości wód (jednostki) } \\
\hline & $\begin{array}{c}\mathrm{pH} \\
\text { (jedn. } \mathrm{pH} \text { ) }\end{array}$ & $\begin{array}{l}\text { Temperatura } \\
\text { wody }\left({ }^{\circ} \mathrm{C}\right)\end{array}$ & $\begin{array}{c}\text { ChZT-Cr } \\
\left(\mathrm{mg} \mathrm{O}_{2} \cdot \mathrm{dm}^{-3}\right)\end{array}$ & $\begin{array}{c}\mathrm{BZT}_{5} \\
\left(\mathrm{mg} \mathrm{O}_{2} \cdot \mathrm{dm}^{-3}\right)\end{array}$ & $\begin{array}{c}\mathrm{Cl}^{-} \\
\left(\mathrm{mg} \mathrm{Cl} \mathrm{dm}^{-3}\right)\end{array}$ \\
\hline Atlantycki & 7,92(I) & $14,2(\mathrm{I})$ & $35(\mathrm{IV})$ & 3,80(III) & $1208(\mathrm{~V})$ \\
\hline Baltycki & 7,89(I) & $15,0(\mathrm{I})$ & 32(IV) & $3,75(\mathrm{III})$ & $839(\mathrm{~V})$ \\
\hline Trymerski & $7,88(\mathrm{I})$ & $14,4(\mathrm{I})$ & 38(IV) & $3,69(\mathrm{III})$ & 1253(V) \\
\hline
\end{tabular}

Objaśnienia: I, III, IV, V - klasyfikacja wartości badanego wskaźnika wg kryteriów Rozporządzenia Ministra Srodowiska z dnia 11 lutego 2004 r.

\section{REZULTAT I WNIOSKI}

Wody basenów portowych Portu Świnoujście w okresie prowadzonych badań posiadały wartości $\mathrm{pH}$ były lekko zasadowe - w całym okresie badawczym zostały zaliczane do I klasa jakości wód wg kryteriów Rozporządzenia Ministra Środowiska z dnia 11 lutego 2004 r.

W ekosystemach wodnych badanych basenów badana wartość ChZT-Cr kształtowała się głównie na poziomie dla wód III i IV klasy jakości.

Wskaźniki mineralizacji wód badanego jeziora cechowały się ustabilizowanym stężeniem badanych makroskładników jonowych wody na poziomie V klasy jakości wód.

W całym okresie badawczym tj. 2004 - 2008 wody basenów portowych Portu Świnoujście posiadały wskaźniki oceny jakości wód od I klasy do V klasy jakości. Z uwagi na narażenie basenów portowych Portu Świnoujście na zanieczyszczenia związane z przeładunkami jakie odbywają się na jego terenie - zboża, rud, olejów, celulozy, drobnicy węgla, żelaza, należy prowadzić badania oceny jakości wód tych basenów, aby można na bieżąco ocenić stan wód tych akwenów. 


\section{Polskie Normy}

PN/C-04540.03. Badania wartości pH, kwasowości i zasadowości. Oznaczanie kwasowości i zasadowości mineralnej i ogólnej metodą miareczkowania wobec wskaźników.

PN/C-04578.02. Badania zapotrzebowania tlenu i zawartości węgla organicznego. Oznaczanie chemicznego zapotrzebowania tlenu ChZT.

PN/C-04586.03. Oznaczanie żelaza ogólnego i rozpuszczonego w zakresie $0,02-10 \mathrm{mg} / \mathrm{dm}^{3}$ metodą kolorymetryczną z 1,10-fenantroliną lub 2,2'-dwupirydylem.

PN/C-04617.02. Oznaczanie chlorków w wodzie i ściekach metodą argentometrycznego miareczkowania.

PN/C-04632.03. Ogólne zasady pobierania próbek do badań fizycznych, chemicznych i biologicznych. Technika pobierania próbek.

PN/C-04632.04. Ogólne zasady pobierania próbek do badań fizycznych, chemicznych i biologicznych. Utrwalanie i przechowywanie próbek.

PN/C-06504. Przygotowanie roztworów buforowych.

\section{Podziękowania}

Autorzy artykułu pragna podziękować za możliwość przeprowadzenia badań na akwenach basenów portowych Portu Świnoujście oraz udostępnienie wyników badań Laboratorium Badań Środowiska Pracy Zarządu Morskich Portów Szczecin i Świnoujście.

\section{References}

[1] Barik S.K., Purushothaman C.S., Mohanty A.N., Aquacult. Res. 32 (2001) 819-832.

[2] Bowden K. F., Oceanic and Estuarine Mixing Processes. W: Riley J. P., Skirrow G. (eds.), Chemical Oceanography. London-New York-San Francisco 1974, 1-41.

[3] Buchholz W., Zmienność stanów i przepływów w ujściach rzek na przykładzie ujścia Odry. Materiały Sesji Naukowej KBM PAN. Szczecin 1990, 49-70.

[4] Buchholz W., Materiaty do monografii Dolnej Odry. Warunki hydrologicznohydrodynamiczne. Prace IBW PAN, Gdańsk, 22 (1990) 1-117.

[5] Daniszewski P., International Letters of Chemistry, Physics and Astronomy 1 (2012) 6-12.

[6] Daniszewski P., International Letters of Chemistry, Physics and Astronomy 1 (2012) 13-16.

[7] Daniszewski P., International Letters of Chemistry, Physics and Astronomy 2 (2012) 42-45

[8] Daniszewski P., International Letters of Chemistry, Physics and Astronomy 2 (2012) 46-52. 
[9] Daniszewski P., International Letters of Chemistry, Physics and Astronomy 2 (2012) 35-41.

[10] Demel K., Życie morza. Gdańsk 1974.

[11] Dojlido J. R., Chemia wód powierzchniowych, Wydawnictwo Ekonomia i Środowisko 1995.

[12] Druet C., Elementy hydrodynamiki geograficznej, Warszawa 1995.

[13] Elbanowska H., Zerbe J., Siepak J., Fizyczno-chemiczne badania wód. Wydawnictwo Naukowe PWN: 1999, ss. 232.

[14] Grasshoff K., , Methods of Seawater Analysis. Weinheim-New York 1976.

[15] Hermanowicz W., Dojlido J., Dożańska W., Koziorowski B., Zerbe J., Fizyczno-chemiczne badanie wody $i$ ścieków, Arkady, Warszawa 1999

[16] Jasińska E., , Dynamika słonych wód w estuariach polskich rzek. Inst. Budownictwa Wodnego PAN, 24 (1991) 1-206

[17] Kajak Z., Hydrobiologia-Limnologia. Ekosystemy wód śródlądowych, PWN, Warszawa 1998, ss. 355.

[18] Leybovich S., Ulrich D., J. Geophys. Res. 77 (1972) 1683-1688.

[19] Lyman J., Chemical consideration, physical and chemical properties of sea water. Washington 1959, cited after: Monin A. S., (red.), Chimija okieana. T. 1, Chimija wod okieana. Moskwa 1979.

[20] Majewski A., (red.), Zalew Szczeciński. Warszawa 1980.

[21] Majewski A., Charakterystyka hydrologiczna estuaryjnych wód u polskiego wybrzeża. Prace PIHM, 105 (1972) 3-37.

[22] Majewski A., Charakterystyka hydrologiczna Zatoki Pomorskiej, Warszawa 1974,

[23] Mikulski Z., , Udział wód rzecznych w stosunkach hydrologicznych Zalewu Szczecińskiego. Biul. PIHM, 5 (1960) 1-23.

[24] Mikulski Z., Wody śródlądowe w strefie brzegowej południowego Bałtyku. Biul. PIHM. 1970,

[25] Młodzińska Z., Zawartość tlenu. W: Majewski A. (red.), Zalew Szczeciński. Warszawa, (1980) 223-230.

[26] Młodzińska Z., b, Hydrochemia. W: Majewski A. (red.), Zalew Szczeciński. Warszawa, (1980) 248-277.

[27] Port Świnoujście. Urząd Morski w Szczecinie. 2008.

[28] Port w Świnoujściu - nabrzeża. Zarząd Morskich Portów Szczecin i Świnoujście SA. 2009. 